\title{
Coworking spaces as talent hubs: The imperative for community building in the changing context of new work
}

\author{
Marko Orel $^{1}$ (D) Manuel Mayerhoffer ${ }^{1} \cdot$ Jana Fratricova $^{2} \cdot$ Anna Pilkova $^{2}$. \\ Marzena Starnawska ${ }^{3}$. Dora Horvath ${ }^{4}$
}

Received: 2 August 2020 / Accepted: 29 July 2021 / Published online: 9 August 2021

(c) The Author(s), under exclusive licence to Springer-Verlag GmbH Germany, part of Springer Nature 2021

\begin{abstract}
Coworking spaces are flexible and shared work environments that make a significant effort to connect users with supportive networks that commonly result in efficient work outputs, a high level of collaboration and knowledge transfer. Recent years have seen swift growth and popularisation of the coworking model, making these spaces an integral part of local entrepreneurial ecosystems and transforming them into the localised pools of specialised talent. However, little research has been conducted to understand the role of human talent in coworking spaces, indicating a knowledge gap in human resource management and the role of contemporary coworking environments. Therefore, the purpose of the following paper is to contextualize coworking spaces as (local) talent hubs by investigating how they tend to build their identity on their userbase. The manuscript explores the managerial practices and mediation techniques by presenting empirical evidence and subsequent analysis of talent attraction and retention mechanisms commonly used in coworking environments. The study shows that by facilitating interaction and collaboration between users, coworking spaces offer support throughout the business life cycle and identify themselves as local accelerators of entrepreneurship and talent development within their local environments.
\end{abstract}

Keywords Talent Management · Talent Development · Human Resource Management $\cdot$ Human Capital $\cdot$ Identity

Mathematics Subject Classification 90B70 · 90B50

Marko Orel

marko.orel@vse.cz

Extended author information available on the last page of the article 


\section{Introduction}

After the turn of the millennium, the last two decades have seen expeditious changes in how knowledge work is conducted with telecommuting and frequently isolating remote work practices increasingly becoming a new standard amongst various types of workers (Golden 2009; Bentley et al. 2016; Golden and Gajendran 2019; Wang et al. 2020). In parallel, contemporary coworking spaces, thoroughly flexible and towards collaboration orientated workspaces, have seen a significant increase in popularity amongst workers who sought engaging office grounds where they could 'work along together' (Spinuzzi 2012) while seeking social support (Gerdenitsch et al. 2016) and collectivization (Avdiikos and Iliopoulou 2019) by actively or passively interacting with one another (Parrino 2015; Rus and Orel 2015; Grazian 2020). Due to the increasing demand, coworking spaces have soon started to appear both in urban and rural environments (Merkel 2015; Nakano 2020), seemingly transforming various micro-locations into centres for highly skilled and knowledgeable workers (Orel 2020; Grazian 2020; Mariotti et al. 2021; Migliore et al. 2021).

In 2017, the American business magazine Inc. reported on a growing trend of large companies identifying coworking environments as talent pools that can be used to enhance their recruitment efforts. Three factors appear to have fuelled this trend: First is the fact that millennials, who make up more than 30 percent of the U.S. workforce, strongly prefer these collaborative and open environments as their daily workplaces. With similar numbers and trends spanning across Europe, the projection by the European Union indicates that by 2030, these hyper-connected, commonly tech-savvy millennials will make up to $75 \%$ of the total workforce and most likely seek active networks of highly skilled individuals who can support them with obtaining new skills, open new connections or assist when shifting career path (European Union 2020). Flexible, open-to-all and multigenerational offices such as coworking environments seem to have the capacity to tackle these trends (Lowell and Morris 2019; Buchnik and Frenkel 2021). Second, coworking spaces provide greater autonomy and productivity, and are heavily frequented by highly specialised freelance and independent workers. And third, coworking environments make a significant effort to connect their users with supportive networks that result in more efficient teamwork than one might typically find within larger organisations (Dukes 2017).

The emerging trend of recognising coworking environments as hubs for highly skilled individuals is already noticeable within the industry. Jessica Miller-Merrell, one of Forbes' top 50 social media influencers, announced an investment in a coworking space as a springboard for establishing a talent pool of skilled workers who could be outsourced by partner companies (Miller-Merrell 2017). Di Risio (2019), a manager from the technology solutions firm Kisi, has drafted a strategic framework for coworking companies to improve their chances of attracting top talent at their locations. Among the recommendations are specialisation to attract specific groups of users (e.g., developers, architects, writers, etc.), embracing sustainability (for various teams identifying with the coworking space's plan) and 
investment in wellness (to offer amenities in addition to a well-designed office, which could help the workspace stand out in a competitive market). However, it is essential to note that these sources are embedded within broader reasoning of attracting working individuals to coworking spaces as paying customers and not exclusively to generate human talent hubs. Thus, a more in-depth analysis is needed.

While the industry has witnessed these rapid changes, academia has undertaken very little research to understand human talent's role in coworking spaces. As coworking environments have emerged in response to the global economic transformation over the past two decades (Orel and Dvouletý 2020), two versions of the flexible office arrangement have begun to appear (Tremblay and Scaillerez 2020). Studies indicate that the generally smaller, independently owned coworking spaces tend to focus on developing internal networks, creating a supportive community of peers who shape the identity of the environment together (Bouncken et al. 2018; Mayerhoffer 2020). In contrast, franchised or multi-location coworking spaces are typically larger, and their footprint spans multiple locations. Venues are selected based upon their surrounding talent pool, and the franchise seeks to attract skilled workers through the use of various incentives (Hochberg 2016; Bandinelli and Gandini 2019). The effectiveness of each approach, however, remains poorly understood. Moreover, coworking spaces have been repeatedly seen to be largely beneficial for their users as they connect individuals in supportive and collaborative networks. However, the mechanisms that mediate interactions and group actions, and subsequently attract prosperous users to work in a selected coworking space for a prolonged period, have not been thoroughly studied yet.

The latter suggests a knowledge gap in the field of human resources between management (HRM) and recruitment as to the role of contemporary coworking spaces. First, it is not entirely clear how human talent is perceived within coworking environments, or how (and why) human skills are mapped to commence a recruitment process. Second, it is vital to recognize the factors that attract skilled individuals and groups to a particular setting, and what differences exist between the mediated and non-mediated mechanisms that are used to appeal to this target audience. This paper will explore managerial practices and mediation techniques, based on a sample of coworking spaces within the four countries in the Central and Eastern Europe (CEE) region, which attract highly-skilled individuals, interlace them in supportive networks and utilize their talent. The purpose of the following work is to (i) understand the role of coworking spaces in the context of human resource management, (ii) investigate how coworking spaces build their identity through the support of the development of specialized human talent, and (iii) explore mechanisms that are being used to attract and retain human talent. By answering these questions, the following research contribution is a clarification of how coworking spaces can—and if—-be identified as local human talent hubs.

\section{Literature review}

The paper opens up with a brief meta-narrative review of the available literature on human talent and coworking spaces. This method provides a glimpse into a particular research tradition that has unfolded over time and examines the range of 
approaches to comprehensively study an issue to create an account of the subject's development (Gough 2013). What is more, the meta-narrative review enables the production of a synthesis that embrace the many complexities of a selected subject by including both scholarly and non-scholarly sources (Greenhalgh et al. 2005). The approach enables drawing a coherent story within the scope of a heterogeneous topic across the paper. It builds on various, often overseen sources such as single papers, conference contributions and industry reports. These sources may have examined a particular subject differently due to taking unalike approaches or building their understanding on different conceptual frameworks. Understanding contrasting perspectives and inconsistent approaches enables a scholar to dive into a particular subject with an over-arching narrative that opens up space to further explore an identified knowledge gap (Wong et al. 2013).

With that in mind and to gain insight into past and current trends in human talent among coworking environments, we draw upon non-peer-reviewed news sources to seek implications, peer-reviewed research to understand the past investigation related to our inquiry, as well as relevant industry reports that may share data-driven insight into the field.

First, we explore how human resource management (HRM) is perceived in the context of the open talent economy where independent professionals seek to utilize their skills and knowledge, and subsequently craft a set of new opportunities in a technology-enabled and borderless market. Second, we visit past studies that directly or indirectly investigated human resource management in the context of coworking spaces. The latter aims to provide a backdrop for the subsequent empirical exploration of talent pool developments through a range of mechanisms that enable coworking managers to identify, recruit and retain highly skilled talents, and interlace them into networks that support the utilization of their expertise.

\subsection{HRM in the open talent economy}

The structural changes caused by seismic market shifts in recent years are reshaping both the demand and supply of talent and are transforming human resource strategies. Companies are finding that the hiring process is frequently complicated by the global shortage of skilled labour (Oxford Economics 2012). Despite these challenges (or perhaps because of them), an open talent economy has emerged. This collaborative and technology-laden method of conducting rapid-cycle business through ecosystems and networks has paved the way for organisations to recruit ondemand talent (Schwartz et al. 2013). Businesses face increasing pressure to become acquainted with this novel approach to recruiting and widen their identification of alternative pools of untapped talent (Hagel et al. 2017).

There are generally four types of talent that hiring managers can consider when it comes to their on-demand workforce. First, balance-sheet talent is the traditional view of corporate work and is typically denoted by a full-time employee of the organisation. The worker is expected to follow the conventional line of career opportunities within the selected organisation. Second, borrowed talent is labour that is recruited via contracted outsourcing through another organization. Third, freelance 
talent commonly refers to the self-employed and other forms of independent workers. They possess expertise for a particular position or role and can complete a team for a selected work process. Fourth and finally, open-source talent refers to the labour of individual workers, or a community of workers, who are able and willing to provide specific knowledge to the organisation, and are engaged free of charge (Storey et al. 2005; Schwartz et al. 2013; Ribeiro and Machado 2017; Poon 2019).

Various talent types appear in different places and within different networks, prompting organisations to construct highly flexible and adaptable recruiting strategies. The open talent economy has contributed to a shift from organisations "owning" talent to organisations seeking to access that talent (Stephan 2008; Collings et al. 2019; Dirani and Nafukho 2018). This technology-enabled mindset has permitted organisations to democratise the strategic approach towards the cycle of talent attraction and recruitment, allowing for the alteration of the standardised human resource cycle. HR activities such as recruitment, selection, development, and retention of employees could be shifted to talent pools containing relevant expertise as sought by a particular organisation. However, these talent pools would require a capacity to attract individual workers, map their skills, connect them to relevant networks and construct a sense of belonging to retain them (Mäkelä et al. 2010; Avey et al. 2011; Seopa et al. 2015). It is important to note at this point that the underlying meaning of talent is reflected within organisations, and across organisational boundaries, industries or countries because discourses arise and materialise within specific contexts and we must acknowledge that talent discourses cannot be removed from the context in which they operate (Wiblen and McDonnell 2020).

Due to the high fluctuation in the need for (and availability of) on-demand workers, organisations tend to seek out highly motivated individuals. The objective is to promote "organisational citizenship behaviour"-a concept that refers to voluntary, positive and constructive contributions by members to the organisation that recruits them (Organ, 2018). As the open talent economy pushes individuals to work in borderless workplaces (Mihalcea 2017) and with on-demand workers generally being less attached to their employer due to the lack of a standard employment relationship (Kalleberg 2000; Keuskamp et al. 2013), an individual's level of emotional engagement and affinity with the recruiting entity may be questionable. Thus, it should come as no surprise that businesses recruiting within the open talent economy often target individuals who have already established identification with that organization and commit to their line of work (Hassan 2012; Coetzee et al. 2019).

Rus and Orel (2015) suggest that flexible work environments such as communitybased coworking spaces can replicate the sense of belonging that motivates workers to apply themselves to the task at hand. Garrett et al. (2017) note that many users find in their coworking spaces the feeling of community that can elude freelancers or independent contractors, who often lack the sort of camaraderie one associates with a conventional worksite. Furthermore, Bouncken et al. (2020) propose that the successful alignment of social space and workplace can empower the individual and contribute to a sense of satisfaction with one's work, helping to foster the entrepreneurial spirit and innovative potential of highly-skilled workers. This, of course, presumes that coworking spaces could indeed emerge as talent hubs that can play an essential role in allocating individuals with the skill sets being sought. 


\subsection{Coworking spaces in the context of talent management}

When Lazar Džamić, a lecturer at Business School Lausanne, gave a keynote speech at 2019's Coworking and Coliving Conference CCCSEE on identifying human resources in contemporary, flexible workspaces, he emphasised that talent is recognised solely in a particular environment and could be overlooked in other generic settings (Džamić 2020). In other words, flexible workspaces such as coworking environments may host individuals possessing a knack and aptitude for specific skills. However, without a clear strategic framework for spotting, developing and sharpening those talents, these workspaces would not gain any tactical advantage in the labour market as potential talent pools.

Existing literature suggests that talent identification has been associated with flexible, drop-in workspaces from the Renaissance onward. Formica (2017) presents evidence on 15th-century bottegas, or workshops that sprouted up in Florence in which master artists, architects, engineers, anatomists and other skilled craftsmen supported and mentored younger, talented peers. Bottegas utilised three main tools to develop new talent. First, they enabled talented individuals to use fully-equipped and shared workshops to turn ideas into action. Second, they actively fostered dialogue between skilled workers to help them expand their network. Lastly, they facilitated the convergence of art and science by creating a holistic approach to creativity.

Fast-forwarding to the nineteenth century, when similar collaborative workspaces flourished across France, seasoned craftsmen established and managed shared studios to support local communities of gifted artists. Orel and Dvouletý (2020) report that the primary tool for helping skilled individuals has been the everyday use of shared physical spaces. Senior artists have taken on the role of mediators to accelerate informal interactions, and nurtured the development of supportive networks, transforming these studios into early creative hubs. Over the next century, these workspaces gradually began to specialise, hosting homogenous communities where knowledge and other resources could be shared. The Writers Room, a New Yorkbased, café-styled environment for talented writers, first opened its doors in the 1970s. Its founders had a clear plan to support accomplished individuals and further developed their strong points. Another example is found in the first contemporary hackerspace, Berlin-based C-base. This shared workspace is intended for people with interest in technology and computing, and offers an organisational culture that supports the value of collaboration through the sharing of knowledge, equipment, and ideas (Lindtner et al. 2014).

Contemporary coworking spaces emerged at the dawn of the twenty-first century. Schraubenfabrik, a community centre for entrepreneurs, opened in Vienna, Austria, in 2002 (Makaklı et al. 2019). Three years later, Spiral Muse, believed to be one of the earliest modern coworking spaces, opened its doors within the San Franciscobased collective house of the same name (Spinuzzi 2012; Merkel 2015). The concept began to proliferate, and coworking quickly gained popularity in the ensuing decade, in part due to socioeconomic changes which served to support its growth (Schmidt et al. 2014; Cabral and Winden 2016). By the end of 2019, there were an estimated 22,400 such workspaces worldwide (Mazareanu 2019). While the early coworking spaces have much more profiled communities of members, it appears 
that the swift popularisation of coworking spaces around the world have somewhat eased on the gatekeeping trend that narrated who and when to accept in the workspace and allow the integration in its inner network. Waters-Lynch and Potts (2017) contend that coworking spaces have thrived due to their becoming focal points for allocating people, ideas and other resources, and connecting them in tightly-knit networks. Bouncken and Görmar (2021) report that companies are constantly looking for new ways to improve their innovation capacity and that the virtues of coworking environments can strengthen and complement the company's business orientation. Gerdenitsch et al. (2016) suggest that coworking environments' highly flexible infrastructure enables users to access social support through various onsite mechanisms. This trend has positive implications for enhanced entrepreneurial performance (Bouncken and Reuschl 2018), which is crucial for independent workers who need to tackle a vast array of challenges in marketing their services.

It is, however, not entirely clear how coworking spaces construct their strategies to build talent pools as strategic assets, and the said mediation mechanisms do not solely serve to attract users as paying customers. It appears that coworking environments have taken on a dual role when it comes to human resource management. First, coworking spaces are commonly seen as optimised, cost-effective and appealing workspaces that bolster an employee's well-being (Spreitzer et al. 2017), expand their skillsets (Van De Vrande and Hynes 2016), increase work flexibility (Merkel 2015), and promote work-life balance (Johri and Teo 2018). These benefits serve to motivate users (Brown 2017) and make them more productive (Marchegiani and Arcese 2018). Second, coworking environments have successfully adapted to the demands of the new economy, employing various tactics to attract particular target workforces to their spaces, which in turn leads to the formation of tightly knit social networks (Rus and Orel 2015; Bianchi et al. 2018; Spinuzzi et al. 2019). Scholars commonly perceive these networks of support as collaborative communities (Merkel 2015; Castilho et al. 2017; Spinuzzi et al. 2019) that enable the development of users' entrepreneurial potential, assisting them to compete in the open markets. In other words; through a precisely curated third place, a community-orientated social environment (Brown 2017), individuals are presented with the possibility to continue working alone but together in a group setting (Spinuzzi 2012). The latter can be a product of spontaneous or mediated interactions. However, these interactions are moderated either through direct interventions by community managers, coworking space employees who deploy selected strategies to deploy social capital formation (Cabral and Winden 2016), or indirectly using workspace setting and its spatial comfortability (Orel and Almeida 2019).

In a similar matter, Waters-Lynch and Duff (2019) argued that coworking ambivalence is a product of immaterial labour of individuals who regularly use a coworking environment, implying that an open-based and curated workplace can ease the transfer of explicit and implicit knowledge as previously indicated by Bouncken et al. 2018). Furthermore, Cnossen and Bencherki (2019) suggested that a coworking space should be understood as a material assemblage as it participates in providing endurance to organize practice and provides them with meaning, going hand in hand with the organizational culture behind the selected coworking environment that is typically formed on the norms of mutual support, knowledge sharing and 
collaboration (Rus and Orel 2015). What is more, Bouncken et al. (2021) suggest that fostering emotional and social values cannot be achieved solely with the said mediation mechanism, but with the spatial intervention in the form of coworking space's interior design and architecture as these are crucial elements to create the basis for a positive ambience within the workspace. In other words, atmospheres that generally define coworking environments are by and large constituted by the practices of coworking space users who are generating value in these environments. However, the value co-creation does not evolve on the spur of the moment but rather on the high diversity of users that tend to build relationships and strive for highly innovative outcomes (Goermar et al. 2021).

To ensure ideal conditions for both the interaction and the transfer of knowledge to commence, the community manager needs to identify the individuals' needs for comfort (Orel and Almeida 2019) and forge a culture of collaborative interactions (Yang et al. 2019) that is further fortified with the coworking space ambience. The active mediation between the coworking users and achieving a shifting interplay of formal and informal relationships within the workspace can thus provide a basis for collective action (Blagoev et al. 2019) and a sense of community (Garrett et al. 2017). These two - apart from a chance for meaningful encounters-are a common reason why individuals tend to use a local coworking space over working from home or a coffee shop (Jakonen et al. 2017) and could explain the swift popularisation of coworking environments in the last decade prior to the recent developments around the Covid-19 pandemic. To put it in a different perspective; while coworking spaces may indeed attract users as paying customers, they nevertheless generate the basis for developing tightly-knit networks of support and subsequently a pool of various human talents.

These previous findings suggest that today's coworking spaces can be distinguished from their predecessors due to their evolution around users' needs. Kubátová (2016) reports that about ten percent of companies in the West utilise strategies to identify untapped talent pools that can be allocated in coworking centres due to their dynamic development but does not offer any empirical evidence how these organisations approach individuals possessing the sought-after skillsets. By implying that coworking spaces could function as a sort of talent incubator, we can assume that these flexible workspaces have the capacity to become a recruitment centre for highly skilled labour and talent pools in the eyes of larger organizations. Tarry (2018) indicates that talent acquisition could become even more challenging in the future due to the growing demand for highly skilled workers and specialised profiles, and that coworking spaces could serve as potential talent sourcing pools.

Nevertheless, going through the existing sources, it becomes clear that there is a knowledge gap in our understanding of how coworking spaces can serve as catalysts for developing localised supportive communities built around talented individuals. Moreover, it is unknown whether and how the organisational space and brand identity actually serve to attract specific talent that could be recruited in particular contexts. Understanding talent in the context of flexible work environments and the utilisation of possible mechanisms to transform coworking spaces into talent hubs are topics that remain largely unstudied. Scholarly work and commercial resources linking human talent with the coworking model could best be described as scant, leaving 
a widening gap in the field of HRM. That said, there are three questions that we will try to answer within the scope of the following empirical inquiry. First, we will be seeking how coworking spaces tend to identify themselves in the context of human talent. Second, there is the question of how coworking may or may not build a sense of belonging to attract and subsequently retain human talent. And lastly-what are the mechanisms that enable coworking spaces to be identified as talent pools?

\section{Method}

Given the objective of exploring human talent in the context of contemporary coworking environments serving as pools of highly skilled individuals and groups, an in-depth, qualitative interviewing technique was used. The main benefit of the selected method was the richer understanding of the selected subjects and presents a profound way to obtain the data within a relatively unresearched field. Moreover, the qualitative interviewing enabled flexibility and intimacy when talking to interviewees, revealing findings that could otherwise be left uncovered. Interviews were conducted with managers and workspace operators in coworking spaces that are located in Central and Eastern Europe, set across the four countries of the Visegrád region-The Czech Republic, Slovakia, Poland and Hungary. The setting of the socalled "Visegrád Four" has been selected due to the thriving economic landscape (Ivanová et al. 2018; Gubik and Farkas 2019) and a rapidly growing flexible office space market that results in a varied landscape of coworking environments (Kovács and Zoltán 2017; Šebestová et al. 2017; Isac 2019; Mayerhoffer 2020).

To diversify the sample, varying types of coworking spaces were selected. As seen in Table 1, ten coworking spaces are purposed for individual use, six have been designed primarily for groups of users, and four have been established as a launching pad for start-up companies. According to the taxonomy of contemporary coworking spaces as proposed by Orel and Bennis (2021), the first type of workspace aims to host independent professionals who are free to work from any location. The group-purposed coworking spaces mainly target corporate groups that seek a workspace with limited openness and socialise primarily on a more formal level. The final type aims to promote the success of users who, for the most part, represent small teams whose businesses are in the early stages of their life cycle.

Data collection took place in two stages. First, the principal investigator conducted a thorough literature review and prepared a singular interview guide protocol that has been devised into five sections totalling fourteen basic questions. Every part of the interview included probing questions as a "jumping off" point for topic discussions, enabling the interviewer to explore different matters and dissimilar strategic approaches towards talent management. Interviewers sought to understand: (i) how different coworking spaces are perceiving the human talent; (ii) how the identity of a particular coworking space is being built to attract a specific type of individual; (iii) how coworking spaces are mapping skills and how are these skills being connected into skillsets; (iv) what specific mechanisms are being used to attract and retain skilled individuals; and finally (v) how the selected coworking spaces are 


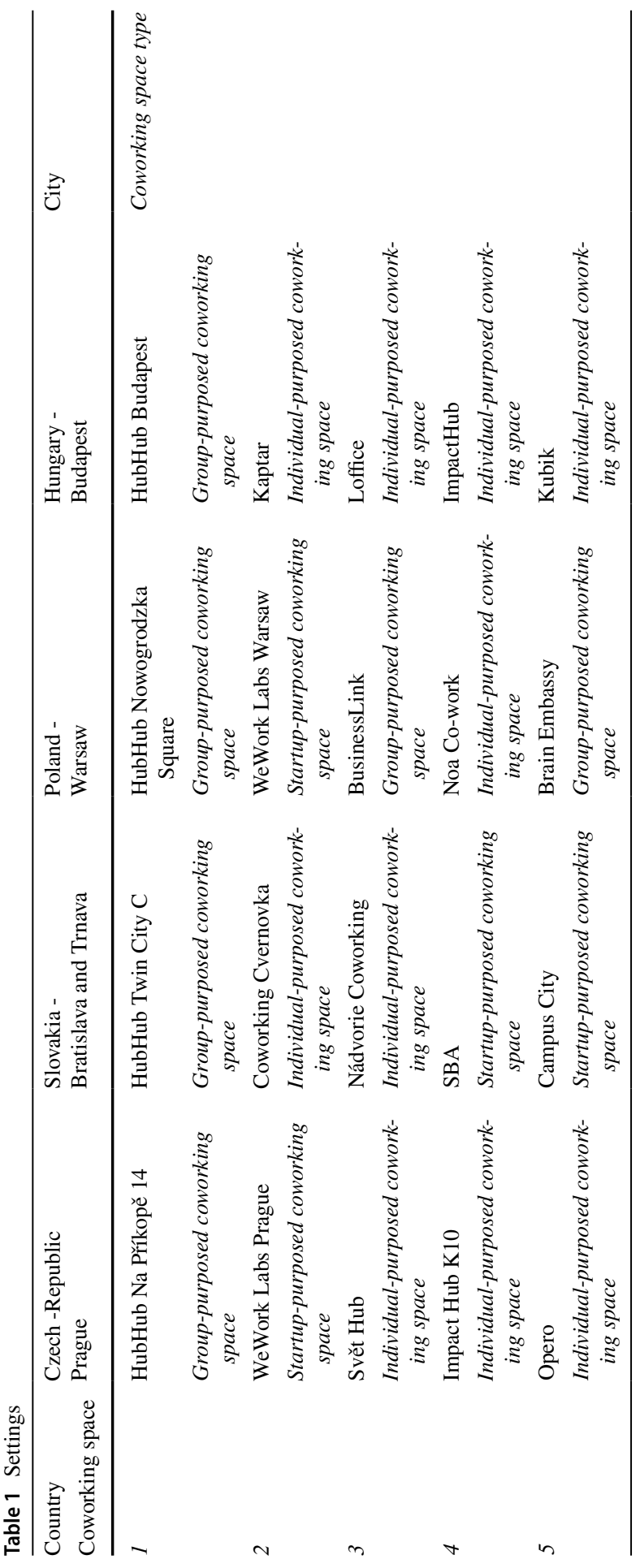


strategically approaching the possible establishment of talent pools and the ultimate utilisation of mapped talents for inner and outer sourcing.

Next, 20 interviews with general managers were conducted on location at selected coworking spaces by four regional scholars. All of the discussions were undertaken in the local languages, since the ability of the respondent to express themselves and comprehend the interview in their mother tongue is essential to conducting research that is both rigorous and culturally competent (Fryer 2019). Discussions were recorded and transcribed by the interviewers, with transcripts subsequently being translated into English for analysis and comparison of the data. The total length of the recorded interviews was 1,225 min, with the average conversation lasting $61.25 \mathrm{~min}$. There were no disagreements between the scholars who have collected the data.

\section{Analysis}

The translated transcripts were returned to the principal investigator for analysis. Since the data collected was complex and texturally rich, the examination was conducted using template data analysis, a methodology of thematic analysis that involves a high degree of structure. The centre of this technique is developing a coding template in the form of a conceptual framework (King 1998). Several examples from prior workspace studies utilising this approach (e.g., Phipps et al. 2009; Viotti 2016; Morrison and Smollan 2020) emphasise a hierarchical coding, encompass narrower and more specific themes, and utilise a clear overview of relevant findings that elucidate previously unexplored fields (Table 2).

The transcripts were read multiple times by three researchers, who independently identified key themes of the interviews with the coworking space managers. The key themes were subsequently discussed and continuously challenged by the researchers during weekly meetings, from which a total of eight main themes emerged: community, brand identity, talent attraction mechanisms, talent selection mechanisms, talent development and retention mechanisms, talent mediation mechanisms, space organization, sourcing of talent by externals and members. Upon further discussion, the themes were synthesized into a working model, which was further refined upon completion of the coding process, and focused solely on themes and sub-themes which were cited in at least ten of the interviews. In taking this approach, the final version of the model was re-validated through a final round of discussion by challenging the model against transcripts to determine fit.

\section{Results}

\subsection{Community}

The respondents allude to a focus on providing a framework for the functioning of the community of their members. They note that shared values among users, and generally accepted rules for interaction, enable them to co-create a sense of 

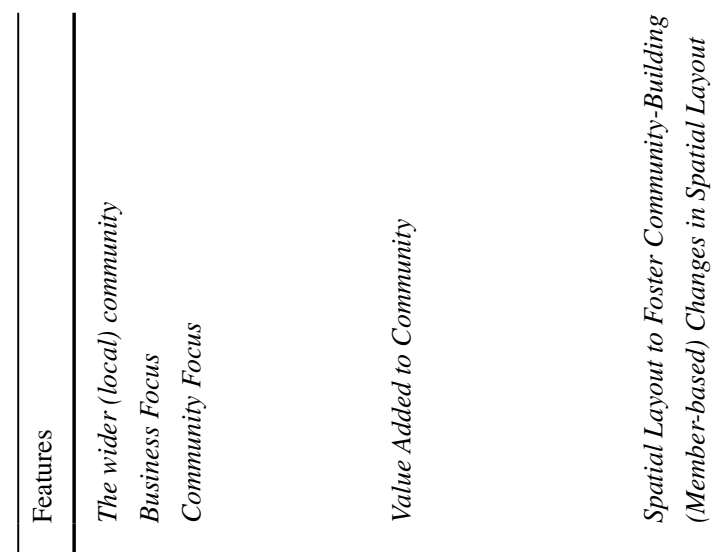

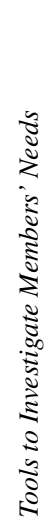

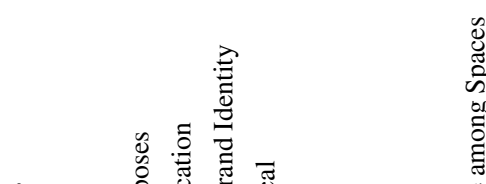
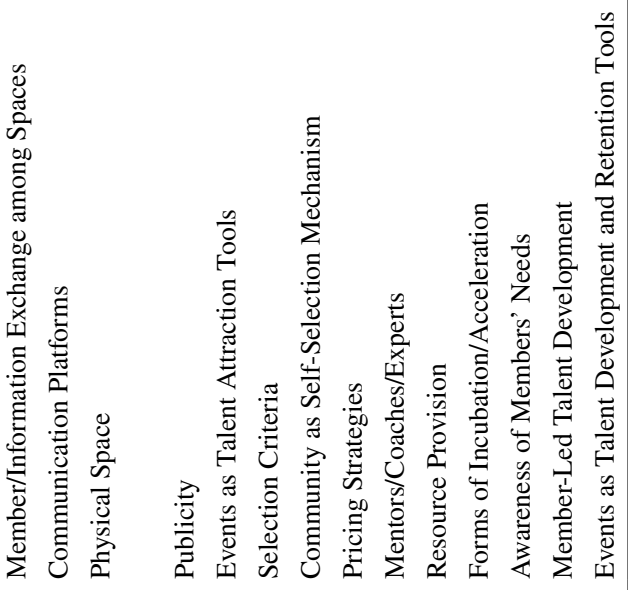

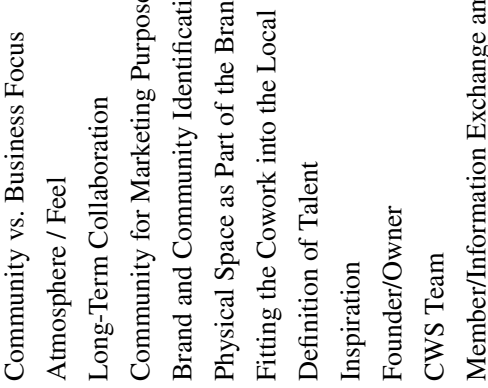

总 |
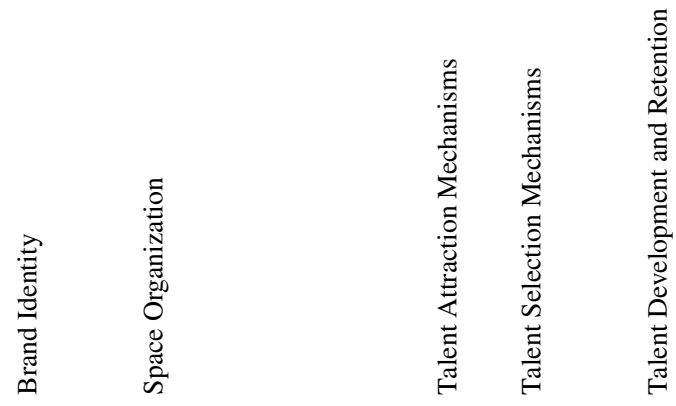


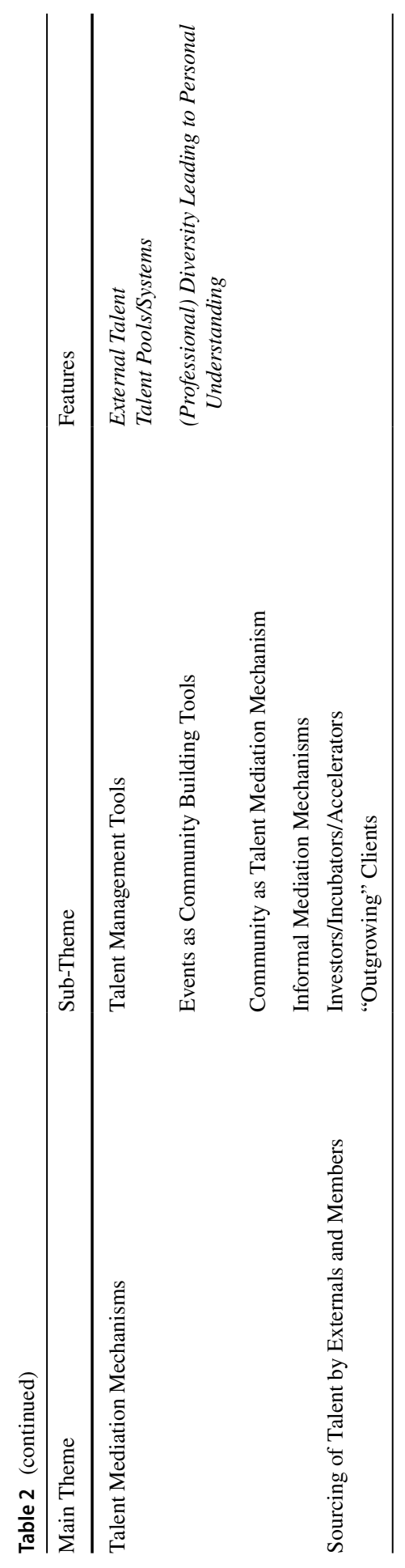


community. The interviews suggest that coworking spaces can be positioned along a "Community vs. Business Focus" continuum, with a primary focus either on community building to foster collaboration of members and enhance well-being, or on growing the coworking space through rapid expansions, both locally and internationally. The interviews shed light upon the goal of community-focused workspaces, namely, the growth of one's own enterprise by and through the community's organic growth. The following quote illustrates this further:

"So, the aim is not only to move our business forward but also to move their business forward and to enrich one another, and all in all to move forward."

(HubHub Prague).

In addition to the focus on either the community or the business, there are degrees of attention to the wider (local) Community evident in the pursuit of supporting "positive social change" (ImpactHub Budapest). Coworking spaces perceive themselves as initiators and accelerators of movements and broader communities, either focusing on a specific theme such as entrepreneurship, or on a more comprehensive mission such as environmental impact or social justice. In particular, those spaces operating as subsidiaries of a larger enterprise (e.g., HubHub under HB Reavis; Brain Embassy under Adger) seem to naturally lean towards the Business Focus side of the continuum. These workspaces face more pressure to generate returns through the growth of their clients' businesses, often to refer clients to the parent company, from which the clients can lease office space. In contrast to the business focus, workspaces on the Community Focus side of the continuum treat the building of community as "the most important thing" (Kubik Budapest). These spaces encourage personal growth, and advocate collaboration among members to create a tight-knit community that shares values and interacts on a meaningful basis. Business growth may be part of the plan, but it is not necessarily a driving force.

The Atmosphere / Feel within the coworking space emerged as a significant subtheme. The operators are keenly aware of its importance: "Thanks to the creation of a friendly atmosphere here.... We are trying to find ways how we can activate the people here. So that they could experience this synergy" (Noa Co-work Warsaw). In trying to create a setting that cultivates productivity and familiarity, members seem to soak up the atmosphere, leading to boosts of motivation and synergies among members. This is furthered by the focus on Long-term Collaboration between members and the workspace, with the spaces investing in the relationship with their members by supporting them throughout their business life cycle.

What results from this process is a feeling of organisational citizenship, where individuals can learn and businesses can thrive. This even extends to former members, or "alumni" (Kaptar Budapest) who return to the space for special events. Establishing such a community makes it possible for the spaces to utilize the Community for Marketing Purposes, as word spreads and the space organically gains new members who are interested in becoming part of the ecosystem: "And because everything we offer is available to all members, the community then interconnects organically, the community sparks interest internally but also externally, I mean that people's interest in what happens here grows." (WeWork Prague). This mechanism is further reinforced by the members' Brand and Community Identification, with the 
feeling of pride that comes with a sense of belonging to relevant target groups. The following quote illustrates this effect in place at HubHub in Bratislava:

"It means that when I introduce somebody to someone else, they say "this is a HubHub member" and I identify myself as a member of a group. The objective is to make that group strong and prestigious so that people want to belong to it; that it's going to be a quality sign, a sign that you qualify somewhere."

\subsection{Brand identity}

A space's brand identity emerged from the interviews as a key element in positioning the coworking space in the market and attracting talent. By developing and further advancing their own DNA, and actively communicating this through public relations efforts, workspaces can differentiate themselves in the local market, with a focus on their global standing. Similarly, the spaces establish the Physical Space as Part of the Brand Identity, opting for a unique interior which also becomes advantageous for members looking to impress guests that they invite to the space, as outlined by Brain Embassy in Warsaw:

"They also said that the membership here influences business relationships in a very positive way. You have a client who is entering this space and there is something to talk about at the very first instance. There is nothing like "how was your trip", but rather "wow!" as a reaction to the place. Brainers [name for their members] tell us that it has a very positive influence on the quality of these meetings."

Moreover, the physical space aids the functioning of the brand identity in attracting their target group. For the latter, the sub-theme of Fitting the Cowork into the Local emerged, which further outlines how the space is configured to the local needs and market dynamics. Despite a centralized strategy of larger coworking space operators, they nevertheless suggest an adaptation based on the given local context. SvetHub in Prague explains it in this way:

"We are a small coworking space, that is distinct ... how to say this, it's based on people who live close by, they've been coming here for a long time, it's not any in-and-out sort of place. People have been members for at least a year, they tend to be members for months or years at a time, it's usually for more than half a year."

To more effectively draw their target group into the space, the brand identity seems to be built around a Definition of Talent of their ideal members. This ranges from an emphasis on hard skills to a softer understanding of talent as innate by looking primarily for "somebody with talent" (HubHub Bratislava). A key criterion appears to be the Value added to the Community, which comprises both soft and hard factors. The following quote exemplifies this:

"The profile of the "dream" client is a person who is open. It is someone who likes to talk about their business, likes to build relationships, is happy to coop- 
erate, so cares about this space, feels engaged here. Although it is us who are supposed to provide services and service here.... this feeling of comm.....of belonging...” (Noa Co-work Warsaw).

\subsection{Talent attraction mechanisms}

Following the coworking space's conscious positioning in the local talent market and narrowing down the requirements for members, the goal is to fill the space with the most suitable members. With an initial membership base, the space solidifies its market position, allowing for an organic, non-mediated attraction of talent as new members fitting the profile are drawn into the space:

"When you have an attractive tech company, other tech companies follow, and hiring, I don't want to use this word because we don't do hiring, but I mean that it becomes easier to attract top tech companies, they start responding when they find out you are already developing a tech community and you already have some tech startups.” (HubHub Prague).

This is further aided by active Publicity through engagement on social media channels, investment in SEO and Adwords, while also relying on organically generated word of mouth of members attracting further candidates from the desired target group. In addition to this, Events as Talent Attraction Tools function by opening the space to the general public, enabling guests to engage with members. The respondents stress this as perhaps the most critical tool to generate new members, suggesting an inevitable return on investment whereby, in addition to enlarging the membership base, networking further contributes to the development and growth of current members:

"Actually, we are able to convert people who take part at an event to our (wide) community, to our clients or connect them to someone within our community. The events can be the biggest channel I would say, it's quite important." (Campus City Bratislava).

\subsection{Talent selection mechanisms}

With a focus on full occupancy of the space, coworking spaces actively assess candidates in line with the respective policies and strategies of the space to determine their fit, both in terms of the community and the prospective member's skill set, as highlighted in the following quote:

"The goal at the end of the day is that when we are fully occupied and will be able to choose who will be here, that the candidates will have to qualify." (HubHub Bratislava).

For assessment purposes, the sub-theme of Selection Criteria emerged, which, in line with the underlying understanding of talent within the space, narrows down 
the profile of the ideal member to be selected by the staff member in charge, for instance, based upon specific personality traits:

"It is more of intuition. I can feel if someone has a natural personal culture, conduct.... Or not... If I have more people who apply for the space here... I actually use such personal criteria. Some people call it "chemistry". This chemistry usually grows in personal relationship but there is an assumption here that in Noa co-work we also work on more familiar basis." (Noa Co-work Warsaw).

Furthermore, respondents hint at the Community as a Self-Selection Mechanism. Hence, a non-mediated process, where prospective members get to develop a feeling for the space's atmosphere and members either during an event, or while making use of a free trial day. When that sense of synergy is lacking, they de-select and no longer wish to become members:

\begin{abstract}
"And somehow, those who don't share our approach go away, and it happens organically, which I like. I think that in the course of our existence we decided to say good-bye to two members. And usually, the people who go away don't share our mindset, they don't enjoy the relaxed, pleasant and friendly space, they prefer to be on formal terms, they prefer an enclosed office and a hotellike services that we don't provide. They leave because they might be dissatisfied, the place is not a good fit for them and that's completely fine, because we can't accommodate everyone and we have some boundaries that we can cross and that we can't cross." (ImpactHub Prague).
\end{abstract}

The third selection parameter is the pursuit of Pricing Strategies, in particular setting prices in higher market segments, with which the coworking spaces further narrow down their target group to individuals, small teams, or other businesses with stable growth and income, and in doing so, turn away candidates with less financial stability: "Please also remember that the price, the fee does the job. We do not have the whole spectrum of the society." (WeWork Warsaw).

\title{
5.5 Talent development and retention mechanisms
}

The respondents outline how coworking spaces assume "the role of an educator, of a change maker" (Brain Embassy Warsaw) for their members in helping them advance both in terms of their personal growth, as well as their businesses. By making use of internal and external Mentors/Coaches/Experts, the coworking spaces actively develop their members in a mediated process:

"We have a database of mentors. So, when he [the business] comes to me and says "We have grown up and we need help with financial matters", I will say that $O K$, here is the CFO of Microsoft, I can connect you. Thus, top people in the country to whom they would never get a chance to get, these people teach or convey their knowledge, and for them it is again that HubHub forms a gateway-they know that when we link them to someone, it is not going to be just 
anybody from the street who wants something and a there is a filter in place."

(HubHub Bratislava).

To further enable the development and retention of members, Resource Provision is considered a necessity to allow members to focus on developing their potential fully. Such resources range from basic amenities such as high-speed internet and coffee, to more customized service offerings:

"It sounds ridiculous but it's basics, and if this doesn't work well, everything else we're trying to build falls to pieces.” (ImpactHub Prague).

An additional approach taken in the development of members is the establishment of Forms of Incubation/Acceleration within the coworking spaces, supporting individuals and businesses in various stages of their business life cycle. This, in turn, also benefits the coworking spaces through the expansion of their network and draws interest from investors. In the pursuit of maximizing the benefits from talent development and retention mechanisms, Awareness of Members' Needs is described as a crucial element and a continuous effort to tailor their offerings to the changing needs of their members. The following quote highlights this point:

"Every company has needs. You can have a first impression that there is a marketing agency that is doing very well but after a conversation like this it turns out there are some problems that they have not addressed, and that we can actually help them. This is, in fact, the source of our activity." (HubHub Warsaw).

For this purpose, a variety of Tools to Investigate Members' Needs are utilized, ranging from surveys to feedback meetings or less formal chats. In addition to the space's own development efforts, Member-Led Talent Development functions through community initiatives by members, for members, and is actively encouraged by the coworking space. These may also take the form of Events as Talent Development and Retention Tools, either covering a specific, business-related topic, or other inspirational topics. These events are offered free of charge to members, who also get the opportunity to interact with fellow members, or network with guests who pay to join the events:

"And because everything we offer is available to all members, the community then interconnects organically, the community sparks interest internally but also externally, I mean that people's interest in what happens here grows. Well at least three times a week, we host an event for all our members. And because we don't rent out our space externally, this is also an added value for the people who sit here because they organize their own events or presentations here. And when, for instance, our startup decides to have a presentation here, the whole building can attend. So, they become known to the community and once they are known to the community, somehow organically the information is passed on." (WeWork Prague).

The combination of these mechanisms allows coworking spaces to develop their members, and in doing so, ensure the retention of talent. 


\title{
5.6 Talent mediation mechanisms
}

Another way that workspaces actively develop members is through the use of talent mediation mechanisms. As coworking space members make connections with each other, they find new opportunities for personal and professional growth. In the words of an analogy shared by HubHub Warsaw, "We like to give the fishing rod, not the fish. We try to connect people; we try to help them take advantage of one another's skills".

This process is aided by the use of Talent Management Tools. These entail selective invitations for External Talent to connect with members. Some spaces also report that they are being directly contacted by external parties looking to engage. Talent Pools/Systems are provided as a digital tool, where members create profiles and search through the member database. By filtering for skills, location, interests and the like, meaningful relationships can be built even across locations and countries. This directly feeds into the functioning of Community as Talent Mediation Mechanism, with the active exchange of ideas. Ideally, this results in collaboration among members, as illustrated by Noa Co-work in Warsaw:

\begin{abstract}
"There are also some "higher level" things such as interactions .... For example, since this open space is a shared space, people get to know one another in different constellations. Sometimes their professions are complementary and they can start some cooperation. For example, a designer with a software developer can create projects together. It is the most common example. But also, the professions that are similar take advantage of sharing things in common here. They have similar problems; they can consult each other. So, it is a nice value added, apart from using this space. They can even consult their ideas with other people."
\end{abstract}

This is portrayed as flourishing further with (Professional) Diversity Leading to Personal Understanding among members from different backgrounds. The final aspect in creating the necessary framework for effective talent mediation consists of Informal Mediation Mechanisms where coworking space staff actively contribute to creating a friendly, open environment with informal interactions among members, nudging them to connect with others:

"Maybe just a small percentage of people who are outgoing, open, will start talking to others in the street.... But really it is just a small percentage of such people... majority of people need support. I come here: "Hi", "hi".. "what's up?" With this approach I open other people .... They notice that there is somebody else next to them ... that a conversation can be interesting... that even when you have a small talk something can happen later on... it is really hard work, the work of community teams, you know..." (Brain Embassy Warsaw). 


\subsection{Space organization}

A second key element within the space is its organization, both from an operational perspective and from a strategic/visionary perspective. To enhance the functioning of the space, the operators look for Inspiration by travelling to other coworking spaces or meeting with community managers from other spaces, as described by Kubik Budapest:

"I used to do a lot of overseas viewing of what they do, how they do it. I've just been to Tel Aviv, and there was a WeWork, I went to look around, very designer offices, I've collected a lot of ideas from them before, but it's getting harder to figure out what's new."

The Founder/Owner exerts a strong influence over the shape of the coworking space, fashioning it in line with their personal ideals and needs, as noted by the cofounder and current owner of SvetHub Prague:

"So, I designed this space so I myself could use it, and the design is built on my own needs and it reflects my personality that likes to connect these diverse sectors."

To better run the space, the owners hire a Coworking Space Team (CWS Team) with similar values to nurture the community and its atmosphere. Both members and coworking space operators benefit from Member/Information Exchange among Spaces, where members can use multiple locations of the larger coworking chain, and coworking space operators may also exchange knowledge with non-related spaces. Such exchanges are made possible by the spaces' self-perception not as competitors, but as part of a larger ecosystem of local, independent centres who "complement one another rather than compete with one another" (Noa Co-work Warsaw). Other space organization elements include the use of Communication Platforms for members to engage one another. These tend to be digital platforms, such as Slack or Facebook, but can also be internal systems specifically designed for the space. Lastly, the Physical Space is consciously created with amenities such as kitchenettes, which are described as "the heart of the central point of the space" (HubHub Prague). These areas provide a general Spatial Layout to Foster Community-Building, so that members can chat informally and bond with others. Some spaces even allow for (Member-based) Changes in Spatial Layout to enhance the fit of the physical space to their members' needs.

\subsection{Sourcing of talent by externals and members}

As coworking spaces attract and develop a base of talented members, they draw interest from companies within the broader business environment who seek to contract with some of the members. Similarly, members themselves leverage the coworking space as a talent pool to acquire new employees. One group which actively attempts to source talent from coworking spaces is made up of Investors/Incubators/ 
Accelerators. Some of the respondents describe how they cultivate these sorts of relationships to forward them potentially interesting candidates, such as HubHub Bratislava:

"We try to provide a flexible space and events that can be developmental, also a network of contacts and introducing them to people - their future business partners, investors or mentors."

A more direct benefit of solid talent management of coworking spaces can be observed in the case of ImpactHub Prague, reporting to be approached by externals asking for contacts to fill certain positions, highlighting how building a strong talent pool has built the coworking space's reputation in the business environment. However, the interviewee reports to be protective of the community by not disclosing information directly, and instead giving the choice to members through the approach towards externals outlined below, thus also benefitting members by providing them with new development opportunities:

“...send me info about what you're looking for, and a short piece introducing your company, so that I know who's asking, and I'll share it with the people I think might be interested and they would potentially get back to you"

With talent management measures in place, a common strategy has emerged for members' connection to externals, resulting in "Outgrowing Clients", and thus, in businesses that outgrow the coworking space. In particular, those spaces operating under a larger office space provider (e.g., Business Link under SKANSKA), are able to feed the newly matured business back to the parent company, which can accommodate its growing needs, as explained below:

"If you have a very large enterprise like American Express for example or a large bank. They will certainly aim to have permanent outlets, locations. If they start with us, they will be, in the end, interested in traditional leasing (of office area). Our "marriage" with SKANSKA can secure this as well, as part of our capital group. We can offer some office space for their beginning but later SKANSKA will meet their further demands." (Business Link Warsaw). (Fig. 1)

\section{Discussion}

The findings discussed in this paper lay out a comprehensive model for the functioning of talent mechanisms in coworking spaces. This model consists of four major elements.

First, the conscious building of a strong brand identity for the coworking space is a prerequisite for subsequent talent mechanisms to take effect. Importantly, with its underlying concept of talent specific to the space, the brand identity helps to determine the ultimate effectiveness of talent recruitment efforts by reinforcing the space's connection to the target group of highly skilled workers in that location. Moreover, the relationship between brand identity and talent attraction 


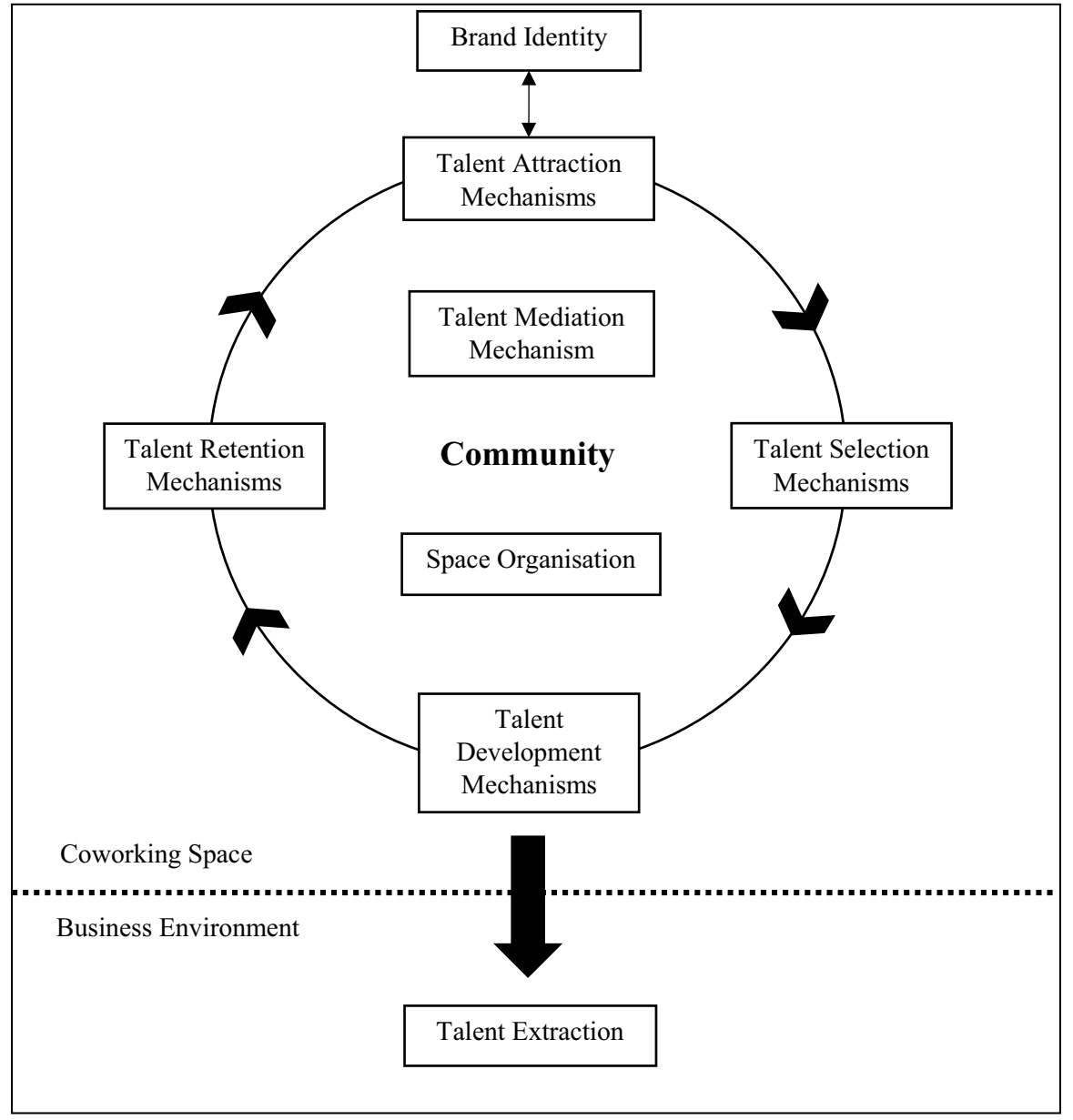

Fig. 1 Model 1. Human talent cycle in coworking environments

mechanisms may be understood as reciprocal, with the brand benefitting from, and being strengthened by, the community of increasingly talented members.

With talent attraction mechanisms as the initiator, the interviews depict a human resource cycle that entails selection, development, and retention efforts by the coworking space. Because this second element is cyclical in nature, it is best understood as an ongoing process which gradually allows a space to maximize its efficacy. Once the space has reached a "critical mass" of talented members, its operators can become more particular in their selection criteria for potential new members. Conversely, they may also begin to de-select underperforming members based on continuous performance reviews as observed in some cases. Furthermore, as talent development and retention efforts become more customized, brand identity is enhanced, and external talent begins to view membership 
as something they should aspire to. In essence, talent attraction begins to take on a life of its own, and these mechanisms' functioning improves over time.

Nevertheless, to optimize the effective functioning of this human resource cycle, the space's organisation and the talent mediation play a crucial role. This third element provides the operational framework to allow for any of the mechanisms to be employed, including that of the physical environment itself, to best cater to its members' varied and changing needs. Talent mediation within the space fuels the effective functioning of talent mechanisms by interlacing members, in both mediated and non-mediated approaches, to build community and enable members to take advantage of any synergies the shared workspace offers.

The fourth and final element of the conceptual model is the continuous sourcing of talent, both by businesses within the space who hire new employees or contract with other members and external businesses who recruit from the co-located talent pool. This is where coworking spaces are able to reap the benefits of the financial and non-financial investments they have made in the functioning and continuous improvement of the human resource cycle. From the perspective of workspace users, this is where their career and business growth are helped most clearly.

\section{Conclusion, Implications of the Study and Directions for Future Research}

The empirical evidence from different coworking spaces is relevant to research on high-performance work systems, and contributes to the study of talent management in relation to coworking environments and their role in labour markets. First, the results have shown that coworking spaces identify themselves as local accelerators of entrepreneurship within communities, contributing to positive social change in their local environments. By facilitating interaction and collaboration between users, coworking spaces offer support throughout the business life cycle, with various lifelong learning and professional growth tools.

Second, the evidence suggests that coworking spaces consciously work to build brand identification and a sense of belonging. The latter stands as the hallmark of an entrepreneurial environment, where individuals can hone their skills and acquire knowledge. Coworking spaces thus become identified as hubs of highly skilled talent by local businesses and policymakers.

Third, in order to realise their potential as talent pools, coworking spaces construct and adapt a vast array of talent attraction, selection and retention mechanisms. The evidence indicates that these mechanisms are different in every workspace, and are generally part of the strategic framework that establishes the position of a coworking space on a local market. Nevertheless, some similarities between the said mechanisms can be identified as they all build their basis on first identifying the talent, recognising the compatibility of the prosperous users and being invested into building meaningful relationships between onboarded users.

This paper can help raise awareness of policymakers about the importance of understanding coworking spaces as contemporary entrepreneurial hubs and help them formulate relevant policies supporting these flexible work environments. 
Moreover, the industry can better understand how different types of coworking spaces operate in terms of HRM, and how they position themselves in the changing landscape of a flexible economy that demands a supply of highly skilled individuals. For practitioners, the outlined talent mechanisms offer an opportunity to be seized. However, they might also be viewed as a threat, pushing them to adopt defensive measures for retaining talent in the face of highly developed coworking competitors. Overall, taking a strategic approach to talent management may benefit coworking spaces, especially in the long-term, due to the nature of the human resources cycle in continuously improving further by enhancing subsequent mechanisms (e.g., successful development and retention improving the brand identity as perceived by potential new members, thus contributing further to attraction mechanisms).

Due to the current COVID-19 pandemic and the resulting shutdown of commerce in many countries during the first half of 2020, the open talent economy has been significantly disrupted. Both traditional and flexible workplaces have been transformed, with the need for social distancing eclipsing the sort of openness and interaction between workplace users previously promoted. Nevertheless, while the coworking industry has been hit particularly hard by the pandemic, coworking environments may yet re-emerge as places offering the sort of flexibility that will be perceived as an asset to local economies. Bureau à Partager, the main platform for connecting individuals and organisations with drop-in workspaces in France, suggests that coworking environments will play a significant role in restarting the flexible economy (Calders 2020). JLL, a commercial real estate service provider has gone a step further, positing that the coworking model will likely take a larger share of the global office market, thanks to its resilience and ability to adapt to the needs of the economy (Huwart 2020). Future development and the changing landscape for flexible workspaces will demand additional research to further delineate the role of coworking environments in human resource management.

There are two possible outcomes to consider in terms of (re)establishing talent pools within coworking environments in the post-COVID-19 world. First, coworking spaces situate their users within a supportive network that is strongly connected to the physical environment. While most of the premises have closed their doors in the opening months of the crisis due to the need for physical distancing, many coworking spaces have initiated virtual coworking sessions for their members in order to maintain connections and nurture a sense of community and belonging (Roussel 2020). Efficient moderation of community-based activities and mediation of relationships might prove to be a go-to tool for retaining individuals within relevant networks. However, the COVID-19 pandemic could change that and a more personalised approach will be needed to attract the very same individuals back to coworking spaces.

Second, early coworking spaces underwent a sort of "growth spurt" following the global economic crisis of 2008 and 2009, with self-employed individuals and independent workers showing a demand for flexible workspaces with access to collaborative networks and new business opportunities. Assuming that coworking spaces can retain their position as talent pools, attract new skilled individuals, and effectively utilise mediation mechanisms that promote connectivity between 
individual members and companies, they could become a focal point for reigniting local economies.

Having said that, an additional scholarly inquiry will be needed. First, it will be essential to understand how smaller, localised and independent coworking spaces may reintroduce the gatekeeping process of selecting individuals who would befit their internal networks of support. Second, with markets being reshaped due to the Covid-19 disruption, coworking spaces may focus on a particular field of knowledge and a specific set of skills and subsequently attract such talent. Third, in parallel to onsite coworking spaces, these spaces may start to actively develop their digital presence, posing the question of how virtual coworking spaces attract individuals and effectively connect them in networks of support.

Supplementary Information The online version contains supplementary material available at https://oi. org/10.1007/s11846-021-00487-4.

\section{References}

Avdikos V, Iliopoulou E (2019) Community-led Coworking spaces: From co-location to collaboration and collectivization In Creative Hubs in Question. Palgrave Macmillan, Cham. https://doi.org/10. 1007/978-3-030-10653-9_6

Avey JB, Reichard RJ, Luthans F, Mhatre KH (2011) Meta-analysis of the impact of positive psychological capital on employee attitudes, behaviors, and performance. Hum Resour Dev Q 22(2):127-152. https://doi.org/10.1002/hrdq.20070

Bandinelli C, Gandini A (2019) Hubs vs networks in the creative economy Towards a 'collaborative individualism' In Creative Hubs in Question. Palgrave Macmillan, Cham. https://doi.org/10.1007/ 978-3-030-10653-9_5

Bentley TA, Teo ST, McLeod L, Tan F, Bosua R, Gloet M (2016) The role of organisational support in teleworker wellbeing: A socio-technical systems approach. Appl Ergon 52:207-215. https://doi.org/ 10.1016/j.apergo.2015.07.019

Bianchi F, Casnici N, Squazzoni F (2018) Solidarity as a byproduct of professional collaboration: Social support and trust in a coworking space. Social Networks 54:61-72. https://doi.org/10.1016/j.socnet. 2017.12.002

Blagoev B, Costas J, Kärreman D (2019) 'We are all herd animals': Community and organizationality in coworking spaces. Organization 26(6):894-916. https://doi.org/10.1177/1350508418821008

Bouncken RB, Görmar L (2021) Entrepreneurial orientation in coworking-spaces for corporate entrepreneurship and venturing. Multidiscip Bus Rev 14(1):84-94

Bouncken RB, Reuschl AJ (2018) Coworking-spaces: how a phenomenon of the sharing economy builds a novel trend for the workplace and for entrepreneurship. RMS 12(1):317-334. https://doi.org/10. 1007/s11846-016-0215-y

Bouncken RB, Laudien SM, Fredrich V, Görmar L (2018) Coopetition in coworking-spaces: value creation and appropriation tensions in an entrepreneurial space. RMS 12(2):385-410. https://doi.org/10. 1007/s11846-017-0267-7

Bouncken R, Ratzmann M, Barwinski R, Kraus S (2020) Coworking spaces: Empowerment for entrepreneurship and innovation in the digital and sharing economy. J Bus Res 114:102-110. https://doi.org/ 10.1016/j.jbusres.2020.03.033

Bouncken RB, Aslam MM, Qiu Y (2021) Coworking spaces: Understanding, using, and managing sociomateriality. Bus Horiz 64(1):119-130. https://doi.org/10.1016/j.bushor.2020.09.010

Brown J (2017) Curating the "third place"? coworking and the mediation of creativity. Geoforum 82:112126. https://doi.org/10.1016/j.geoforum.2017.04.006

Buchnik T, Frenkel A (2021) The lifestyles of millennial coworkers in urban spaces: the case of Tel-Aviv. Eur Plan Stud. https://doi.org/10.1080/09654313.2021.1950641 
Cabral V, Winden WV (2016) Coworking: an analysis of coworking strategies for interaction and innovation. Int J Knowl Based Dev 7(4):357-377

Calders B (2020) Coworking is gradually gaining parts of the regular office market in France. Retrieved from https://socialworkplaces.com/france-coworking-office-market/.

Castilho MF, Quandt CO (2017) Collaborative capability in coworking spaces convenience sharing or community building. Technol Innov Manage Rev 7(12):32-42. https://doi.org/10.22215/timreview/ 1126

Cnossen B, Bencherki N (2019) The role of space in the emergence and endurance of organizing: How independent workers and material assemblages constitute organizations. Human Relations 72(6):1057-1080. https://doi.org/10.1177/0018726718794265

Coetzee M, Ferreira N, Potgieter I (2019) Perceptions of sacrifice, workplace friendship and career concerns as explanatory mechanisms of employees' organisational commitment. SA J Hum Resour Manag 17(1):1-9. https://doi.org/10.4102/sajhrm.v17i0.1033

Collings DG, Mellahi K, Cascio WF (2019) Global talent management and performance in multinational enterprises: A multilevel perspective. J Manag 45(2):540-566. https://doi.org/10.1177/0149206318 757018

Di Risio A (2019) What coworking spaces need to succeed in 2019. Retrieved from https://www.cowor kingresources.org/blog/what-coworking-spaces-need-to-succeed.

Dirani KM, Nafukho FM (2018) Talent management and development: perspectives from emerging market economies. Adv Dev Hum Resour 20(4):383-388. https://doi.org/10.1177/1523422318803362

Dukes E (2017) Want to make employees happy? Make your office like a co-working space. Retrieved from https://www.inc.com/elizabeth-dukes/why-your-workspace-should-be-more-like-a-coworkingspace.html.

Džamić L (2020) Key note: Lazar Džamić “Talent Harvesting The End of Average”. Retrieved from https://www.youtube.com/watch?v=jGWCNtHBudsandt=170s

European Union (2020) Workforce generation changes. https://knowledge4policy.ec.europa.eu/foresight/ topic/changing-nature-work/hyper-connected-tech-savvy-millennials-workforce-rises-2030_en.

Formica P (2017) The innovative coworking spaces of 15th-century Italy. Retrieved from https://hbr.org/ 2016/04/the-innovative-coworking-spaces-of-15th-century-italy.

Fryer CE (2019) An Approach to Conducting Cross-Language Qualitative Research with People from Multiple Language Groups. In: Liamputtong P (ed) Handbook of Research Methods in Health Social Sciences. Springer, Singapore. https://doi.org/10.1007/978-981-10-5251-4_38

Garrett LE, Spreitzer GM, Bacevice PA (2017) Co-constructing a sense of community at work: The emergence of community in coworking spaces. Organ Stud 38(6):821-842. https://doi.org/10.1177/ 0170840616685354

Gerdenitsch C, Scheel TE, Andorfer J, Korunka C (2016) Coworking spaces: A source of social support for independent professionals. Front Psychol 7:581. https://doi.org/10.3389/fpsyg.2016.00581

Goermar L, Barwinski RW, Bouncken RB, Laudien SM (2021) Co-Creation in coworking-spaces: Boundary conditions of diversity. Knowl Manag Res Pract 19(1):53-64

Golden TD (2009) Applying technology to work: Toward a better understanding of telework. Organ Manag J 6(4):241-250. https://doi.org/10.1057/omj.2009.33

Golden TD, Gajendran RS (2019) Unpacking the role of a telecommuter's job in their performance: Examining job complexity, problem solving, interdependence, and social support. J Bus Psychol 34(1):55-69. https://doi.org/10.1007/s10869-018-9530-4

Gough D (2013) Meta-narrative and realist reviews: guidance, rules, publication standards and quality appraisal. BMC Med 11(1):22. https://doi.org/10.1186/1741-7015-11-22

Grazian D (2020) Thank God it's Monday: Manhattan coworking spaces in the new economy. Theory Soc 49(5):991-1019. https://doi.org/10.1007/s11186-019-09360-6

Greenhalgh T, Robert G, Macfarlane F, Bate P, Kyriakidou O, Peacock R (2005) Storylines of research in diffusion of innovation: a meta-narrative approach to systematic review. Soc Sci Med 61(2):417-430

Gubik AS, Farkas S (2019) Entrepreneurial Intention in the Visegrad Countries. Law, Econ Soc Issues Rev 10(4):347-368. https://doi.org/10.2478/danb-2019-0018

Hagel J, Schwartz J, Bersin J (2017) Navigating the future of work. Deloitte Rev 21:27-45

Hassan S (2012) Employee attachment to workplace: A review of organizational and occupational identification and commitment. Int J Organ Theory Behavior 15(3):383-422. https://doi.org/10.1108/ IJOTB-15-03-2012-B002

Hochberg YV (2016) Accelerating entrepreneurs and ecosystems: The seed accelerator model. Innov Policy Econ 16(1):25-51. https://doi.org/10.1086/684985 
Huwart J (2020) Employers will start to see the coworking model as it is their best insurance policy Adam Lis (JLL Poland). Retrieved from https://socialworkplaces.com/coworking-flexibility-insurance/.

Isac C (2019) Coworking spaces: a source for developing creative business. Ovidius Univ Annal Econ Sci Series 19(2):36-41

Ivanová E, Masárová J (2018) Performance evaluation of the Visegrad Group countries. Econ ResEkonomska Istraživanja 31(1):270-289. https://doi.org/10.1080/1331677X.2018.1429944

Jakonen M, Kivinen N, Salovaara P, Hirkman P (2017) Towards an Economy of Encounters? A critical study of affectual assemblages in coworking. Scand J Manag 33(4):235-242. https://doi.org/10. 1016/j.scaman.2017.10.003

Johri A, Teo HJ (2018) Achieving equilibrium through coworking: Work-life balance in FLOSS through multiple spaces and media use. In Proceedings of the 14th international symposium on open collaboration (pp. 1-11). https://doi.org/10.1145/3233391.3233531.

Kalleberg AL (2000) Nonstandard employment relations: Part-time, temporary and contract work. Ann Rev Sociol 26(1):341-365. https://doi.org/10.1146/annurev.soc.26.1.341

Keuskamp D, Mackenzie CR, Ziersch AM, Baum FE (2013) Deliberately casual? Workers' agency, health, and nonstandard employment relations in Australia. J Occup Environ Med 55(6):620-627. https://doi.org/10.1097/JOM.0b013e31829176eb

King N (1998) Template analysis. In: Symon G, Cassell C (eds) Qualitative methods and analysis in organizational research: A practical guide. Sage Publications Ltd, United State, pp 118-134

Kovács JK, Zoltán ES (2017) Rural enterprise hub supporting rural entrepreneurship and innovation-case studies from Hungary. European Countryside 9(3):473-485. https://doi.org/10.1515/ euco-2017-0028

Kubátová J (2016) Human capital of the 21st century in coworking centers. In Proceeding of ECIC 2016 8th European Conference on Intellectual Capital (pp. 145-151).

Lindtner S, Hertz GD, Dourish P (2014) Emerging sites of HCI innovation: hackerspaces, hardware startups and incubators. In Proceedings of the SIGCHI Conference on Human Factors in Computing Systems (pp. 439-448).

Lowell VL, Morris J Jr (2019) Leading changes to professional training in the multigenerational office: Generational attitudes and preferences toward learning and technology. Perform Improv Q 32(2):111-135. https://doi.org/10.1002/piq.21290

Makaklı ES, Yücesan E, Ozar B (2019) Co-working space concept in the spatial and urban context a case study of 'kolektif house.' FSM İlmi Araştırmalar İnsan Ve Toplum Bilimleri Dergisi 14:297-312. https://doi.org/10.16947/fsmia.667316

Mäkelä K, Björkman I, Ehrnrooth M (2010) How do MNCs establish their talent pools? Influences on individuals' likelihood of being labeled as talent. J World Bus 45(2):134-142. https://doi.org/10. 1016/j.jwb.2009.09.020

Marchegiani L, Arcese G (2018) Collaborative spaces and coworking as hybrid workspaces: friends or foes of learning and innovation In Learning and innovation in hybrid organizations. Palgrave Macmillan, Cham. https://doi.org/10.1007/978-3-319-62467-9_4

Mariotti I, Akhavan M, Rossi F (2021) The preferred location of coworking spaces in Italy: an empirical investigation in urban and peripheral areas. Eur Plan Stud. https://doi.org/10.1080/09654313.2021. 1895080

Mayerhoffer M (2020) Growth factors of the coworking industry: the case of Prague. J Property Invest Finance 38(3):203-212. https://doi.org/10.1108/JPIF-12-2019-0164

Mazareanu E (2019) Number of coworking spaces worldwide 2005-2020. Retrieved from https://www. statista.com/statistics/554273/number-of-coworking-spaces-worldwide/.

Merkel J (2015) Coworking in the City. Ephemera 15(2):121-139

Migliore A, Ceinar IM, Tagliaro C (2021) Beyond Coworking: From Flexible to Hybrid Spaces. In The Flexible Workplace. Springer, Cham. https://doi.org/10.1007/978-3-030-62167-4_1

Mihalcea A (2017) Employer branding and talent management in the digital age. Manage Dyn Knowl Econ 5(2):289-306

Miller-Merrell J (2017) What HR needs to do to understand the changing workplace landscape. Retrieved from https://workology.com/hr-changing-work-workplace/.

Morrison RL, Smollan RK (2020) Open plan office space? If you're going to do it, do it right: A fourteenmonth longitudinal case study. Appl Ergon. https://doi.org/10.1016/j.apergo.2019.102933

Nakano D, Shiach M, Koria M, Vasques R, dos Santos EG, Virani T (2020) Coworking spaces in urban settings: Prospective roles? Geoforum 115:135-137. https://doi.org/10.1016/j.geoforum.2020.04. 014 
Orel M (2020) Life is better in flip flops Digital nomads and their transformational travels to Thailand. Int J Cult, Tour Hosp Res 15(1):3-9. https://doi.org/10.1108/IJCTHR-12-2019-0229

Orel M, Alonso Almeida MDM (2019) The ambience of collaboration in coworking environments. J Corp Real Estate 21(4):273-289. https://doi.org/10.1108/JCRE-12-2018-0050

Orel M, Bennis WM (2021) A taxonomy of contemporary coworking spaces. Manuscript submitted for publication.

Orel M, Dvouletý O (2020) Transformative changes and developments of the coworking model: A narrative review In Technological Progress Inequality and Entrepreneurship. Springer, Cham. https://doi. org/10.1007/978-3-030-26245-7_2

Organ DW (2018) Organizational citizenship behavior: Recent trends and developments. Annu Rev Organ Psych Organ Behav 80:295-306. https://doi.org/10.1146/annurev-orgpsych-032117-104536

Oxford Economics (2012) Global Talent 2021. How the new geography of talent will transform human resource strategies. https:/www.oxfordeconomics.com/Media/Default/Thought\%20Leadership/ global-talent-2021.pdf

Parrino L (2015) Coworking: assessing the role of proximity in knowledge exchange. Knowl Manag Res Pract 13(3):261-271

Phipps DL, Noyce PR, Parker D, Ashcroft DM (2009) Medication safety in community pharmacy: a qualitative study of the sociotechnical context. BMC Health Serv Res 9(1):158. https://doi.org/10. 1186/1472-6963-9-158

Poon TSC (2019) Independent workers: Growth trends, categories, and employee relations implications in the emerging gig economy. Empl Responsib Rights J 31(1):63-69. https://doi.org/10.1007/ s10672-018-9318-8

Ribeiro J, Machado C (2017) Global talent management: Reality or utopia? A special glance through a Portuguese multinational organization In Competencies and (Global) Talent Management. Springer, Cham. https://doi.org/10.1007/978-3-319-53400-8_6

Roussel P (2020) Everything about virtual coworking. Retrieved from https://blog.coworkies.com/every thing-about-virtual-coworking/.

Rus A, Orel M (2015) Coworking: a community of work. Teorija in Praksa 52(6):1017-1038

Schmidt S, Brinks V, Brinkhoff S (2014) Innovation and creativity labs in Berlin: Organizing temporary spatial configurations for innovations. Zeitschrift Für Wirtschaftsgeographie 58(1):232-247

Schwartz J, Liakopoulos A, Barry L (2013) The open talent economy. Beyond corporate borders to talent ecosystems. Retrieved from https://www2.deloitte.com/us/en/insights/deloitte-review/issue-13/theopen-talent-economy.html.

Šebestová J, Šperka R, Małecka J, Łuczka T (2017) Co-working centres as a potential supportive network for cross-border business cooperation. Forum Scientiae Oeconomia. 5(4):23-34. https://doi.org/10. 23762/FSO_VOL5NO4_17_2

Seopa N, Wöcke A, Leeds C (2015) The impact on the psychological contract of differentiating employees into talent pools. Career Dev Int 20(7):717-732. https://doi.org/10.1108/CDI-03-2015-0033

Spinuzzi C (2012) Working alone together: Coworking as emergent collaborative activity. J Bus Tech Commun 26(4):399-441. https://doi.org/10.1177/1050651912444070

Spinuzzi C, Bodrožić Z, Scaratti G, Ivaldi S (2019) "Coworking is about community": but what is "community" in coworking? J Bus Tech Commun 33(2):112-140. https://doi.org/10.1177/1050651918 816357

Spreitzer G, Bacevice P, Garrett L (2017) Coworking communities as enablers of thriving at work. Routledge, In The Routledge Companion to Wellbeing at Work. https://doi.org/10.4324/9781315665 979-14

Stephan M, Silvia M, Arie Y, L. (2008) A dynamic perspective on next-generation offshoring: The global sourcing of science and engineering talent. Acad Manag Perspect 22(3):35-54. https://doi.org/10. 5465/amp.2008.34587994

Storey J, Salaman G, Platman K (2005) Living with enterprise in an enterprise economy: Freelance and contract workers in the media. Human Relations 58(8):1033-1054. https://doi.org/10.1177/00187 26705058502

Tarry A (2018) Coaching with careers and AI in mind: grounding a hopeful and resourceful self fit for a digital world. Routledge

Tremblay DG, Scaillerez A (2020) Coworking spaces: New places for business initiatives? Journal of Innovation Economics Management 1:39-67 
Van De Vrande V, Hynes N (2016) Coworking spaces and the breaking of social boundaries to create new forms of innovation. In Academy of Management Proceedings. Briarcliff Manor, NY 10510: Academy of Management. https://doi.org/10.5465/ambpp.2016.16943.

Viotti S (2016) Work-related stress among correctional officers: a qualitative study. Work 53(4):871-884

Wang W, Albert L, Sun Q (2020) Employee isolation and telecommuter organizational commitment. Empl Relat 42(3):609-625. https://doi.org/10.1108/ER-06-2019-0246

Waters-Lynch J, Duff C (2019) The affective commons of Coworking. Human Relations. https://doi.org/ $10.1177 / 0018726719894633$

Waters-Lynch J, Potts J (2017) The social economy of coworking spaces: A focal point model of coordination. Rev Soc Econ 75(4):417-433. https://doi.org/10.1080/00346764.2016.1269938

Wiblen S, McDonnell A (2020) Connecting 'talent'meanings and multi-level context: A discursive approach. Int J Human Res Manag 31(4):474-510. https://doi.org/10.1080/09585192.2019.1629988

Wong G, Greenhalgh T, Westhorp G, Buckingham J, Pawson R (2013) Rameses publication standards: Meta-narrative reviews. J Adv Nurs 69(5):987-1004

Yang E, Bisson C, Sanborn BE (2019) Coworking space as a third-fourth place: changing models of a hybrid space in corporate real estate. J Corp Real Estate 21(4):324-345. https://doi.org/10.1108/ JCRE-12-2018-0051

Publisher's Note Springer Nature remains neutral with regard to jurisdictional claims in published maps and institutional affiliations.

\section{Authors and Affiliations}

\section{Marko Orel ${ }^{1}$ (D) . Manuel Mayerhoffer ${ }^{1} \cdot$ Jana Fratricova $^{2} \cdot$ Anna Pilkova $^{2}$. Marzena Starnawska ${ }^{3}$. Dora Horvath ${ }^{4}$}

Manuel Mayerhoffer

maym03@vse.cz

Jana Fratricova

jana.fratricova@fm.uniba.sk

Anna Pilkova

anna.Pilkova@fm.uniba.sk

Marzena Starnawska

MStarnawska@wz.uw.edu

Dora Horvath

dora.horvath@uni-corvinus.hu

1 Department of Entrepreneurship, University of Economics, nám. Winstona Churchilla 1938/4, Praha 3-Žižkov, 13067 Prague, Czechia

2 Department of Management, Comenius University of Bratislava, Odbojárov 10, 82005 Bratislava 25, Slovakia

3 Entrepreneurship Center, University of Warsaw Krakowskie, Przedmieście 26/28, 00-927 Warszawa, Poland

4 Marketing Media and Design Communication, Corvinus University of Budapest, Fôvám tér 8, 1093 Budapest, Hungary 